Research Article

\title{
A Unified Assessment Approach for Urban Infrastructure Sustainability and Resilience
}

\author{
Liang Wang, ${ }^{1}$ Xiaolong Xue $\mathbb{C}^{1,},{ }^{1,2}$ Zeyu Wang, ${ }^{2}$ and Linshuang Zhang ${ }^{3}$ \\ ${ }^{1}$ School of Management, Harbin Institute of Technology, Harbin 150001, China \\ ${ }^{2}$ School of Management, Guangzhou University, Guangzhou 510006, China \\ ${ }^{3}$ China Mobile Communications Corporation, Shijiazhuang 050021, China \\ Correspondence should be addressed to Xiaolong Xue; xlxue@hit.edu.cn
}

Received 19 April 2018; Revised 13 June 2018; Accepted 25 June 2018; Published 9 July 2018

Academic Editor: Dujuan Yang

Copyright ( $\odot 2018$ Liang Wang et al. This is an open access article distributed under the Creative Commons Attribution License, which permits unrestricted use, distribution, and reproduction in any medium, provided the original work is properly cited.

The concepts of sustainability and resilience have become very popular in the field of urban infrastructure. This paper reviews previous research on sustainability and resilience of urban infrastructure. The concepts of urban infrastructure's sustainability and resilience are compared from the perspectives of dimensions, properties, goals, and methodologies. The paper systematically assesses the sustainability and resilience of urban infrastructure by using the concept of the grade point average (GPA). The GPA of urban infrastructure's sustainability and resilience (urban infrastructure SR-GPA) is proposed as a unified concept. The assessment index system of urban infrastructure SR-GPA is constructed from five dimensions including demand, status, influence, resource, and measure. The analytic network process (ANP) is used to assess urban infrastructure SR-GPA considering the interaction between the indexes. The ANP structure model of urban infrastructure SR-GPA is established based on the assessment method and index system. The Harbin subway SR-GPA is selected as an empirical study to test the applicability of the proposed assessment method. The results show that the assessment indexes have different impacts on urban infrastructure SRGPA. The Harbin subway SR-GPA is in a low level and can be upgraded through increasing construction investment, allocating resources efficiently, and considering resilience in the whole life cycle.

\section{Introduction}

The world is in the process of urbanization since the 20th century, and by far, the majority population live in cities $[1,2]$. People construct numerous urban infrastructures to meet the various needs and challenges for urbanization [3-5]. These urban infrastructures exert significant influence on the global economy and environment and have become central to ensuring a sustainable future $[6,7]$. Meanwhile, people need to confront tremendous technical, economic, and management risks to construct and operate urban infrastructures; therefore, we must build resilient infrastructure to overcome these risks [8]. Therefore, sustainability and resilience of urban infrastructure are vital to urbanization and social development. However, there have been very few researches on how to combine resilience and sustainability in a unified assessment methodology for the design, construction, and operation management of urban infrastructure.

Sustainability has become increasingly important in the civil engineering field with the global development of sustainability since the 1990s $[9,10]$. Although most previous studies support life-cycle thinking in building sector with the model of the three sustainability dimensions and the importance of holistic analysis, fewer studies focus on urban infrastructure compared to building construction [11, 12]. Meanwhile, the concept of resilience is still considered novel and under development in the civil engineering field, and most studies focused on the conceptual and analytical definitions of resilience $[12,13]$.

Although the comprehensive description of resilience has been proposed from 11 different aspects in the civil engineering field, the studies of urban infrastructure's resilience are still under preliminary period $[12,14]$. 
The researches of urban infrastructure sustainability and resilience are inefficient in previous studies. Moreover, there are few efforts to combine urban infrastructure sustainability and resilience into a unified concept.

The main cause of the above issue probably dues to the different historical origins of urban infrastructure sustainability and resilience. The theoretical and practical developments of resilience and sustainability are separate and without a mutual consideration of the findings in most domains [12]. Sustainability focuses on the influence of current behavior upon future development, and resilience emphasizes the response capability to abnormal impact $[15,16]$. The concepts of sustainability and resilience have different historical roots, develop independently in both theoretical and practical field, but generate more and more common connotations as human society develops. Urban infrastructure should have properties of sustainability and resilience simultaneously during the construction and operation process to enhance its capabilities [9]. This study presents an effort to develop a unified concept for both urban infrastructure sustainability and infrastructure. The original contribution of this study consists of a unified assessment approach in order to address the sustainability and resilience of urban infrastructure simultaneously and quantitatively.

The paper is structured as follows: First, previous research on urban infrastructure sustainability and resilience are reviewed and summarized to explain the research motivation. Then, the concept of urban infrastructure SR-GPA is proposed for integrating the concepts of urban infrastructure sustainability and resilience. Afterward, the assessment index system and ANP structure model are constructed to design a unified assessment approach for urban infrastructure SR-GPA. Finally, Harbin subway is selected as an empirical study to test the applicability of the unified assessment approach.

\section{Literature Review}

2.1. Sustainability of Urban Infrastructure. Sustainability reflects the ability to sustain, which means the goal of sustainability is maintaining a state at a certain level [17-20]. The connotation of sustainability varies in different domains [21]. In the field of civil engineering, sustainability mainly refers to sustainable building, which devotes to improving the environmental performance of buildings through technical innovations [22]. Assessment standards enhance the sustainability of buildings, which can be reflected in the improved environmental performance [23]. Further researches have extended sustainability to other dimensions related to human development and emphasize the balance of environment, economy, and society [20, 24].

Current studies of urban infrastructure's sustainability mainly focus on the construction of the assessment index system and the selection of assessment methodology. From the view of whole life cycle, the urban infrastructure system generates interactions and feedback mechanisms with economic and social systems; thus, the assessment standards should be constructed from environmental, economic, social, and engineering dimensions [25]. From the perspective of improving urban infrastructure's environmental performance, the assessment indexes of sustainability can be divided into mandatory screening indexes and judgment indexes, which can be used to improve resource utilization efficiency [26, 27]. In theoretical and practical level, the assessment indexes of urban infrastructure's sustainability should include all dimensions of sustainability, and appropriate index parameters should be selected [28]. Some scholars have specifically studied different urban infrastructures' sustainability, such as lifelines, distributed infrastructure systems, and transportation systems [29-32].

Sustainability of urban infrastructure can be concluded as the unity of environmental, economic, and social dimension. The interactions of these three dimensions form a sustainable urban infrastructure that meets the needs of present and future generations for specific functions and services, and ensures the balanced development of economy, society, and environment.

2.2. Resilience of Urban Infrastructure. Resilience is the ability that a system restores to its original status after being disturbed [33]. The concept has been widely used in different domains (e.g., ecology and environment) [34]. In the field of civil engineering, engineers improve infrastructure's resilience to resist adverse impacts of extreme disasters, such as earthquake and hurricane [35]. Bruneau et al. conceptualize resilience from four interrelated dimensions: technical, organizational, social, and economic [14]. These four dimensions of resilience are described as the TOSE model. The TOSE model quantifies resilience from four properties: robustness, rapidity, redundancy, and resourcefulness [16]. Above four dimensions and four properties form conceptual framework for analyzing resilience. Under this conceptual framework, a resilient system is more reliable and can recover quickly, which ensure low socioeconomic consequences during a disaster [36]. Bocchini et al. systematically summarize the above eleven aspects of resilience for general civil infrastructure [12].

Urban infrastructure's resilience represents the ability that urban infrastructure can recover to its initial status through combinations of technical, economic, and management measures when facing unexpected situations or extreme disasters. Scholars have done research on the calculation and assessment methods of urban infrastructure's resilience from different perspectives which reflect the above eleven aspects of resilience. Various methods, such as simulation [37], mathematical calculation, and quantification method [38], have been used to calculate urban infrastructure's resilience. In addition, the priority of assessment standards should be considered for assessing urban infrastructure resilience, and policymakers' preferences play an important role in determining the assessment standards of resilience $[39,40]$.

Concluded from above studies, the assessment of urban infrastructure resilience should include three dimensions [12]: (1) technical dimension, comprising all technical elements in urban infrastructure life cycle; (2) economic dimension, involving economic factors in the restore processes 
of urban infrastructure; and (3) management dimension, incorporating social and organizational measures in operation and management stages of urban infrastructure. Moreover, the benefits of improving urban infrastructure resilience can be concluded as follows: (1) high reliability: urban infrastructure have lower probability of functional loss in the action of external disasters; (2) fast recovery: urban infrastructure can quickly restore to its normal status after disasters happen; and (3) low socioeconomic consequences: reducing negative impacts on society and economy by speeding up the recovery process of urban infrastructure.

2.3. Summary of Previous Research. Sustainability and resilience have different origins and evolve separately in theory and practice, although they share certain common connotations with the development of human society. There are some similarities between sustainability and resilience in the whole life cycle of urban infrastructure. Bocchini et al. compare similarities and differences between sustainability and resilience in the civil infrastructure domain [12]. The comparison is organized into eleven categories, and the possibility of conflation is evaluated. Due to the different origins, the common definitions of sustainability and resilience are not significantly matching [41]. Sustainability assessment mostly gives a score by using different quantitative and qualitative indicators, while resilience is usually calculated by quantified equation $[42,43]$. These differences of sustainability and resilience cannot completely separate two concepts. Compared with these differences, the similarities between sustainability and resilience are more obvious.

As an important category to use for comparison, the dimensions of sustainability and resilience are perfectly matching. Social and economic dimensions are used for assessing both sustainability and resilience [44]. In addition, the technical and organizational dimensions of resilience are also important for sustainability [45]. At the theoretical level, some important instruments, such as LCC, multicriteria decision-making, can be used to assess sustainability and resilience. At the practical level, the assessment results of sustainability and resilience should be compared with previous reference experience [12]. From the point of view of decision-making, the targets of resilience focus on robustness and rapidity of systems, which can also reduce social and economic impacts [46]. Thus, the targets of sustainability and resilience are also good matching.

As the sustainability and resilience of urban infrastructure share so many similarities, scholars have attempted to combine these two concepts for assessment [47]. Zinke et al. summarize these preliminary attempts to combine sustainability and resilience in infrastructure projects [48]. Some conceptual descriptions are used to apply the properties of resilience on assessing urban infrastructure sustainability $[12,49,50]$. For instance, Turner describes some interesting approaches for combining two concepts in general and with a focus on vulnerability analyses [49]. Despite the fact that some existing schemes, such as British CEEQUAL [51] and American Envision (ISI 2011) [52], are primarily meant for assessing infrastructure sustainability, the assessment approaches described in these schemes also cover aspects associated with some resilience properties. Some sustainability assessment approaches cover risk-associated climate change, even though no further hazard-related consequences are addressed $[53,54]$.

The properties of sustainability are also incorporated in infrastructure resilience analysis. For instance, Ghosh et al. present an approach that combines embodied energy in the assessment of aging infrastructure exposed to seismic hazards [55]. Life-cycle energy assessment (LCEA) is used to extend the life-cycle cost analysis procedure for damages caused by hazards. The concept of sustainability is used to assess infrastructure resilience from environmental dimension. Rose incorporates a few sustainability properties in the concept of posthazard rehabilitation measures [47]. The results manifest improvements in conditions underlying sustainability that have helped in inherent and adaptive resilience associated with disaster recovery. The above analysis shows that urban infrastructure's sustainability and resilience can be considered and assessed together [56].

Urban infrastructure sustainability assessment only analyzes the predictable and regular influences of infrastructure from three dimensions: environment, economy, and society [57]. When infrastructure faces extreme events, infrastructure sustainability assessment is ineffective to enhance infrastructure performance [25]. On the other hand, resilience aims to analyze the responses of infrastructure due to extreme events and the ability of recovery under these circumstances [58]. If urban infrastructure resilience is considered separately on regular circumstances, the status of infrastructure will always be at a high level [59]. The resources will be wasted during the above process, which will have negative impacts on urban infrastructure sustainability [60]. Hence, urban infrastructure should be resilient and sustainable together, but it is very difficult to compare the performance of urban infrastructure by individual resilience assessments or sustainability assessments. A unified assessment approach should be constructed for assessing the sustainability and resilience of urban infrastructure together [12, 61].

\section{Unified Assessment Approach}

3.1. Urban Infrastructure SR-GPA. As mentioned in Section 2.3 , sustainability and resilience have common connotations in whole life cycle of urban infrastructure. From the perspective of sustainability, urban infrastructure needs to meet human needs in normal status and quickly recover in unexpected situations; from the perspective of resilience, urban infrastructure improves the resilient capacity by technical, economic, and management measures, achieving sustainable development. Based on the above ideas, the National Council on Public Works Improvement (NCPWI) assessed the GPA (grade point average) of infrastructure with basic quality and expanding quality [62]. We constructed the unified concept of urban infrastructure's sustainability and resilience using GPA, which was named as the urban infrastructure SR-GPA ( $\mathrm{S}$ is the abbreviation of sustainability 


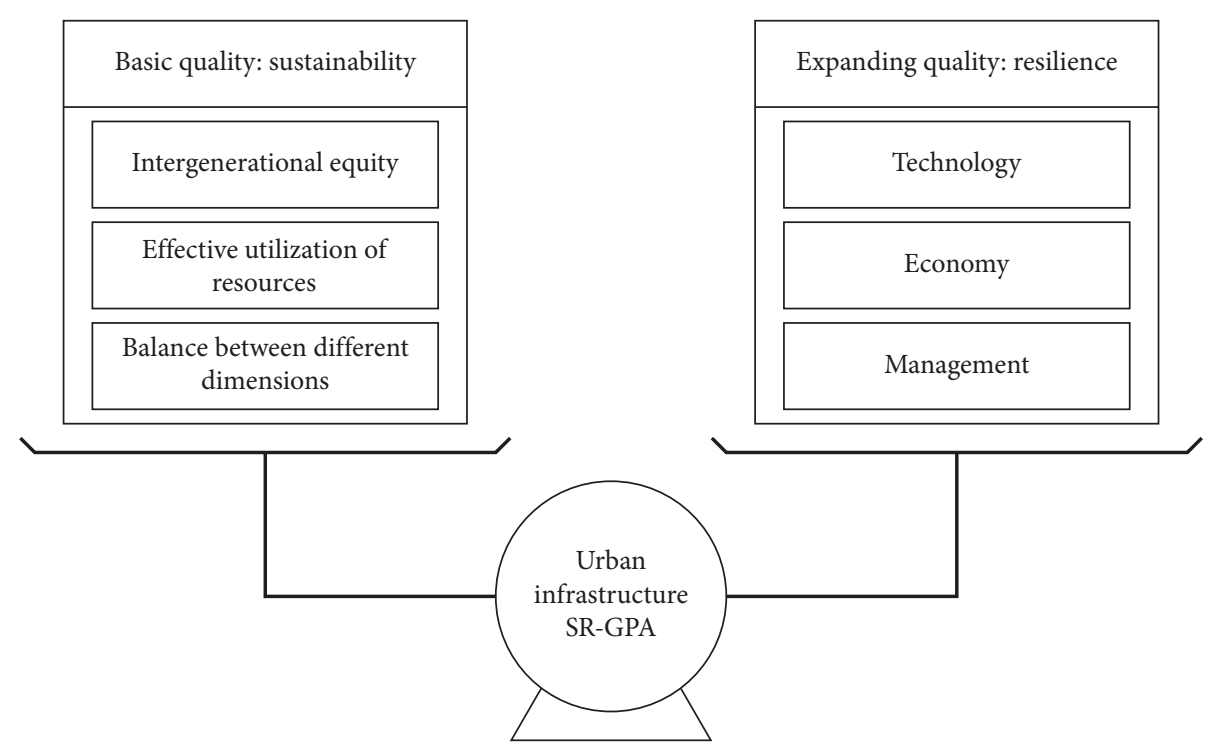

FIgURE 1: The concept of urban infrastructure SR-GPA.

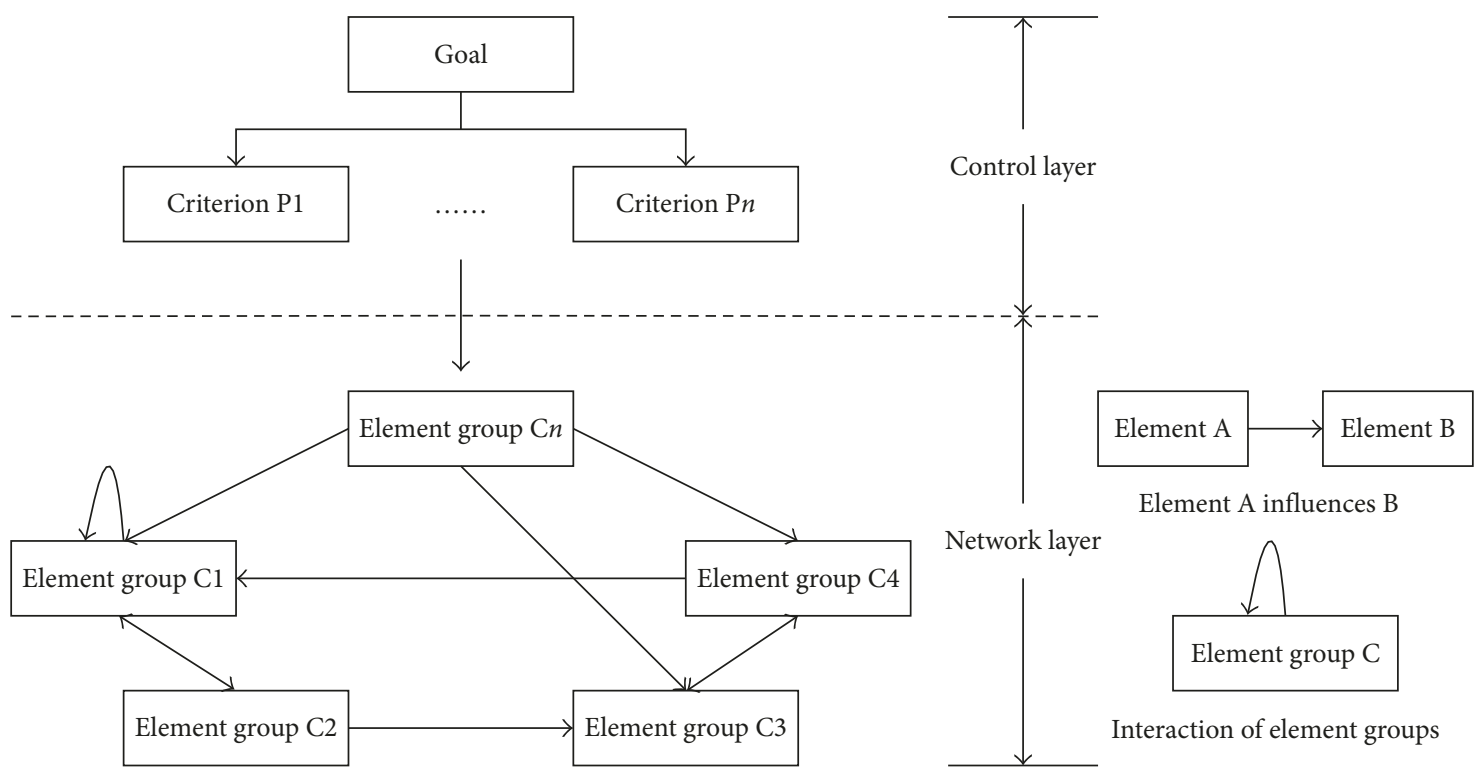

FIgURE 2: The typical hierarchical structure of ANP.

and $\mathrm{R}$ is the abbreviation of resilience). Urban infrastructure SR-GPA is described in Figure 1.

Figure 1 shows that urban infrastructure SR-GPA measures the basic quality and expanding quality of urban infrastructure. The basic quality and expanding quality of urban infrastructure, respectively, reflect its sustainability and resilience. Basic quality requires urban infrastructure to meet human needs in normal status and promote coordinated development which consists of intergenerational equity, effective resource utilization, and balanced economy, environment, and society. Expanding quality requires urban infrastructure to quickly restore to normal status by technical, economic, and management measures after the occurrence of unexpected situations such as earthquakes and hurricanes.
3.2. Assessment Method. The analytic network process (ANP) is a more general form of the analytic hierarchy process (AHP) which is used for multicriteria decision analysis. As ANP allows for complex interrelationships among decision levels and attributes, it has been widely used in infrastructure performance assessment [63, 64]. The composition of the analytic network process is described in Figure 2.

Figure 2 shows that the top element of the hierarchy is the overall goal of the decision model. The hierarchy decomposes from the general to a more specific attribute until a level of manageable decision criteria is met $[65,66]$. ANP consists of clusters, elements, intercluster relations, and interelement relations. ANP reflects interaction and feedback between intracluster and intercluster. ANP contains 


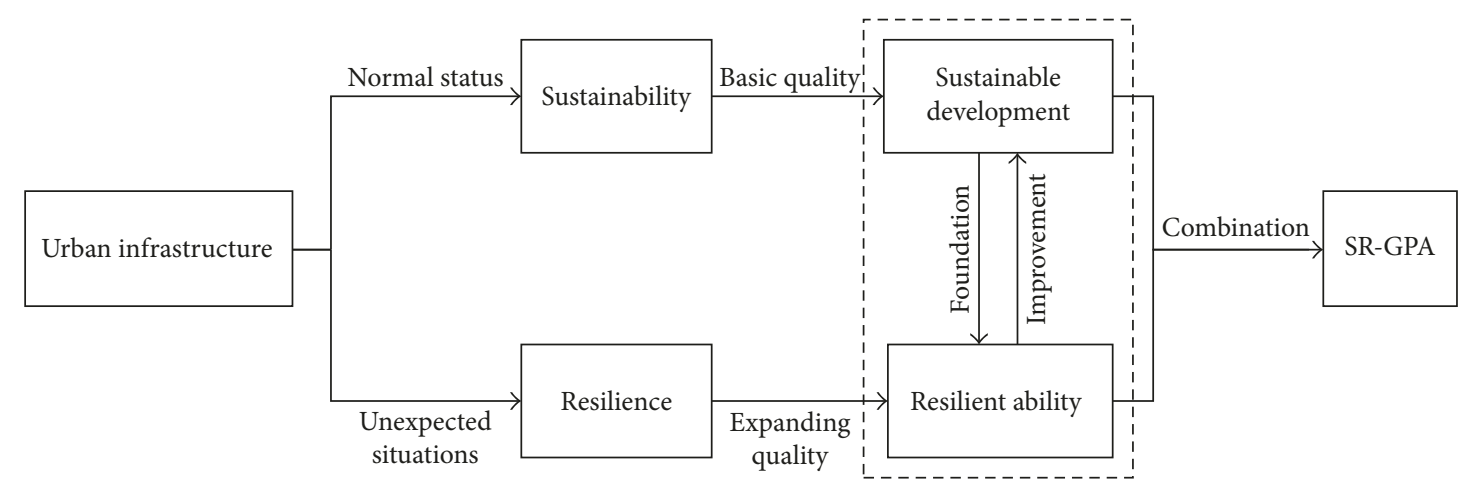

FIGURE 3: Combination framework of urban infrastructure sustainability and resilience.

two layers: the control layer, which includes goal and decision criteria, and the network layer, in which elements constitute mutually influent network structure [67]. Notably, all decisions are independent with each other and are only governed by target elements.

\subsection{Assessment Index System}

3.3.1. Combination Framework. Urban infrastructure sustainability assessment only analyzes the predictable and regular influences of urban infrastructure from different sustainable perspectives in normal status [57]. Traditional assessment methods of urban infrastructure sustainability is ineffective to improve urban infrastructure performance under extreme events [25]. Urban infrastructure resilience aims to analyze the responses of urban infrastructure due to extreme events and the ability of recovery under these circumstances [58]. The status of urban infrastructure is designed at a high level to satisfy the needs of urban infrastructure resilience, which has negative impacts on urban infrastructure sustainable development in normal status $[59,60]$. It is unreasonable that urban infrastructure's sustainability and resilience are assessed separately. A unified assessment approach should be constructed for assessing the sustainability and resilience of urban infrastructure together $[12,61]$. Urban infrastructure SR-GPA is proposed in Section 3.1 as the unified concept of urban infrastructure's sustainability and resilience. $S$ is the abbreviation of urban infrastructure's sustainability, which requires that urban infrastructure should meet the development needs of human society from different sustainable perspectives in normal status [25]. $\mathrm{R}$ is the abbreviation of urban infrastructure's resilience, which requires that urban infrastructure should improve its resilient ability by technical, economic, and management measures in unexpected situations [68]. The combination framework of urban infrastructure's sustainability and resilience is shown in Figure 3.

Urban infrastructure performance is consisted of basic quality and expanding quality. Basic quality represents urban infrastructure sustainability which requires urban infrastructure to meet human needs in normal status and promote coordinated development from different sustainable perspectives [69]. Expanding quality represents urban infrastructure resilience which requires urban infrastructure to quickly recover to normal status by technical, economic, and management measures after the occurrence of unexpected situations [70]. From the perspective of sustainability, urban infrastructure meets human needs in normal status, which is the foundation of urban infrastructure resilience. From the perspective of resilience, urban infrastructure resilience is achieved by technical, economic, and management measures, which can improve urban infrastructure sustainability [12].

Previous studies of sustainable assessment focus on economic dimension, social dimension, and environmental dimension. Urban infrastructure sustainability has transformed from above traditional three dimensions to the following four dimensions: demand dimension [71], status dimension $[72,73]$, influence dimension $[74,75]$, and resource dimension [76-78]. Urban infrastructure resilience is mainly assessed from measure dimension, which reflects that urban infrastructure can quickly recover to normal status by technical, economic, and management measures after the occurrence of unexpected situations $[8,35,79]$. The assessment dimensions of urban infrastructure SR-GPA are shown in Figure 4.

3.3.2. Index Selection. This study develops the assessment index system of urban infrastructure SR-GPA which includes five dimensions: demand, status, influence, resource, and measure. The former four dimensions assess urban infrastructure's sustainability (basic quality), while the measure dimension represents urban infrastructure's resilience (expanding quality). The following sections explain the selection process of the assessment index from the above five dimensions:

(1) Demand Dimension. Urban economic development relies on the support of urban infrastructure. For example, higher urban economic development level requires more comprehensive infrastructures to ensure sustained growth [71]. This study selects the demand dimension index of urban infrastructure from three aspects: city size [80], economic development [25], and social level [81], which are shown in Table 1.

(2) Status Dimension. The state dimension indexes are mainly selected from the two aspects: the supply capacity 


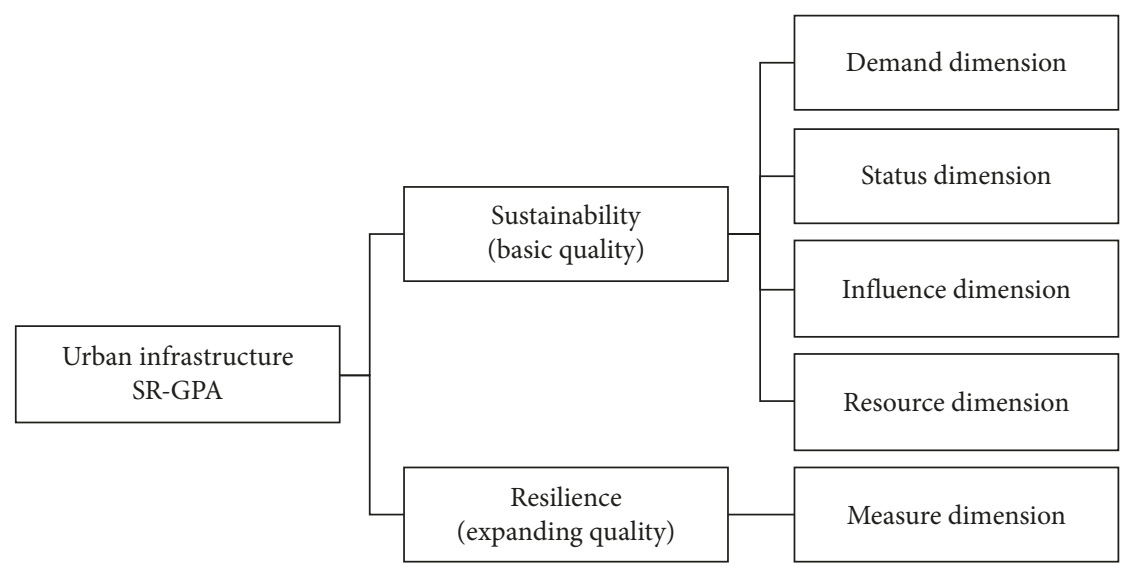

FIgURE 4: Assessment dimensions of urban infrastructure SR-GPA.

TABLe 1: Assessment index of demand dimension.

\begin{tabular}{lcc}
\hline Dimension & Category & Index \\
\hline & D1 city size & D1.1 growth rate of city resident population \\
D2.1 per capita GDP & D2.2 proportion of tertiary industry in GDP \\
Demand (D) & D2 economic development & D3.1 per financial income \\
& & D3.2 per capital expenditure \\
& D3 social level & D3.3 growth rate of infrastructure investment \\
\hline
\end{tabular}

TABle 2: Assessment index of status dimension.

\begin{tabular}{lcc}
\hline Dimension & Category & Index \\
\hline & S1 supply capacity & S1.1 handling capacity \\
& & S1.2 infrastructure density \\
Status (S) & & S1.3 proportion of built-up area in total area \\
& S2 public satisfaction & S2.1 service quality \\
& & S2.2 service price \\
& & S2.3 failure frequency \\
& & S2.4 facility maintenance timeliness \\
& S2.5 facility maintenance quality \\
\hline
\end{tabular}

and public satisfaction. Supply capacity selects three indexes according to the authoritative statistical data published by statistics bureau, which are handling capacity, infrastructure density, and proportion of built-up area in total area $[72,73]$. The three indexes are calculated as follows:

$$
\begin{aligned}
& \text { Handling capacity }(\%)=\frac{\text { the population that urban infrastructure can serve }}{\text { total urban population }}, \\
& \text { Infrastructure density }(\%)=\frac{\text { the urban area covered by infrastructure }}{\text { total urban area }} \\
& \text { Proportion of built - up area in total area }(\%)=\frac{\text { the infrastructure area }}{\text { total urban area }} .
\end{aligned}
$$

Public satisfaction reflects the subjective feelings of the public to the service quality, service price, security, and reliability of urban infrastructure [82]. The assessment indexes of status dimension are shown in Table 2. 
TABle 3: Assessment index of influence dimension.

\begin{tabular}{lcc}
\hline Dimension & Category & Index \\
\hline & I1 goal & I1.1 improve community life quality \\
Influence (I) & & I1.2 stimulate sustainable development \\
& I1.3 develop local technology & I2.1 improve public health and safety \\
& I2 health & I2.2 reduce noise and vibration \\
& & I2.3 reduce light pollution \\
& I3 social environment & I3.1 protect historical and cultural resources \\
& I3.2 protect local characteristics \\
& I3.3 protect the environment \\
\hline
\end{tabular}

TABLE 4: Assessment index of resource dimension.

\begin{tabular}{lcc}
\hline Dimension & Category & Index \\
\hline & & R1.1 reduce material usage \\
& R1 material & R1.2 support sustainable procurement practices \\
R1.3 use renewable materials \\
R1.4 use local materials \\
Resource (R)
\end{tabular}

(3) Influence Dimension. The fundamental purpose of the construction and operation of urban infrastructure is to improve the quality of people's life and promote sustainable development of urban economy and society [74]. The fundamental purpose of the construction and operation of urban infrastructure is to improve the quality of people's life and promote sustainable development of urban economy and society [74]. The influence dimension is further divided into three subcategories: goal, health, and social environment $[25,75]$. The potential impacts should be assessed during the life cycle of urban infrastructure. The assessment indexes of influence dimension are shown in Table 3.

(4) Resource Dimension. Using the efficiency of resources has direct impacts on the sustainability of urban infrastructure because its construction and operation consume large amounts of resources. The assessment indexes of resource dimension, which were developed based on previous research on resource efficiency of urban infrastructure, include three main categories, that is, material, energy, and water. In the construction phase, sustainable infrastructure should efficiently use all materials to reduce the "embodied energy," which is consumed in the process of material production and transportation [76]. In the operation phase, sustainable infrastructure should minimize the overall energy consumption and consider the efficient use of multiple energy sources [77]. Moreover, urban infrastructure should reduce the overall water consumption and consider the positive or negative impacts on water resources [78]. The detailed breakdown of the assessment indexes of resource dimension is shown in Table 4.
(5) Measure Dimension. The assessment indexes of measure dimension mainly reflect the resilience of urban infrastructure, and were selected from three aspects including technical innovation, economic support, and management measures. Technical innovation includes innovations not only in raw materials, products, processes, and equipment but also in the management process and organizational change [79]. The economic support involves in the construction and maintenance of urban infrastructure [8]. On the one hand, the development and use of new materials and technologies, which improve the resilience of urban infrastructure, require a lot of capital. On the other hand, the maintenance, repair, and improvement of urban infrastructure require abundant economic supports. Management measures enhance the resilience of urban infrastructure and ensure urban infrastructure to have a longer service life that meets the future needs [35]. Through the above analysis, the assessment indexes of measure dimension are shown in Table 5.

3.3.3. Index Quantification. The developed assessment indexes include both qualitative and quantitative indexes. Qualitative indexes are difficult to describe with quantitative data, and quantitative indexes can be quantified directly with quantitative data. According to the interaction between index meaning and value, quantitative indexes are divided into benefit indexes and cost indexes. The score of benefit indexes has positive impacts on urban infrastructure GPA, and the score of cost indexes has negative impacts on urban infrastructure GPA. The classification situations of assessment indexes are 
TABle 5: Assessment index of measure dimension.

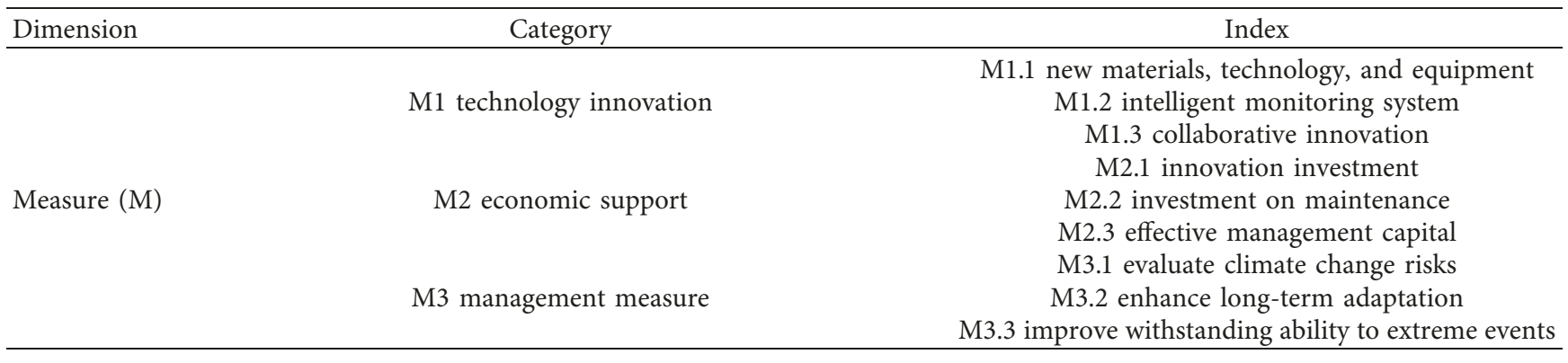

TABle 6: Assessment index system of urban infrastructure SR-GPA.

\begin{tabular}{|c|c|c|c|}
\hline Dimension & Category & Index & Property \\
\hline \multirow{7}{*}{ Demand (D) } & D1 city size & D1.1 growth rate of city resident population & $\mathrm{C}$ \\
\hline & & D2.1 per capita GDP & $\mathrm{B}$ \\
\hline & D2 economic development & D2.2 proportion of tertiary industry in GDP & $\mathrm{B}$ \\
\hline & & D2.3 per capita disposable income & $\mathrm{B}$ \\
\hline & & D3.1 per financial income & $\mathrm{B}$ \\
\hline & D3 social level & D3.2 per capital expenditure & $\mathrm{B}$ \\
\hline & & D3.3 growth rate of infrastructure investment & $\mathrm{B}$ \\
\hline \multirow{8}{*}{ Status $(\mathrm{S})$} & & S1.1 handling capacity & $\mathrm{B}$ \\
\hline & S1 supply capacity & S1.2 infrastructure density & $\mathrm{B}$ \\
\hline & & S1.3 proportion of built-up area in total area & $\mathrm{B}$ \\
\hline & & S2.1 service quality & Q \\
\hline & & S2.2 service price & $\mathrm{Q}$ \\
\hline & S2 public satisfaction & S2.3 failure frequency & $\mathrm{Q}$ \\
\hline & & S2.4 facility maintenance timeliness & $\mathrm{Q}$ \\
\hline & & S2.5 facility maintenance quality & Q \\
\hline \multirow{9}{*}{ Influence (I) } & & I1.1 improve community life quality & Q \\
\hline & I1 goal & I1.2 stimulate sustainable development & Q \\
\hline & & I1.3 develop local technology & Q \\
\hline & & I2.1 improve public health and safety & Q \\
\hline & I2 health & I2.2 reduce noise and vibration & Q \\
\hline & & I2.3 reduce light pollution & Q \\
\hline & & I3.1 protect historical and cultural resources & Q \\
\hline & I3 social environment & I3.2 protect local characteristics & Q \\
\hline & & I3.3 protect the environment & $\mathrm{Q}$ \\
\hline \multirow{11}{*}{ Resource (R) } & & R1.1 reduce material usage & Q \\
\hline & & R1.2 support sustainable procurement practices & Q \\
\hline & R1 save material & R1.3 use renewable materials & $\mathrm{Q}$ \\
\hline & & R1.4 use local materials & Q \\
\hline & & R1.5 dispose and recycle waste & Q \\
\hline & & $\mathrm{R} 2.1$ reduce energy consumption & Q \\
\hline & R2 save energy & R2.2 use renewable energy & Q \\
\hline & & R2.3 monitor the energy system & Q \\
\hline & & R3.1 reduce water consumption & Q \\
\hline & R3 save water & R3.2 reduce domestic water & Q \\
\hline & & R3.3 monitor the water system & Q \\
\hline \multirow{9}{*}{ Measure (M) } & & M1.1 new materials, technology, and equipment & Q \\
\hline & M1 technology innovation & M1.2 intelligent monitoring system & $\mathrm{Q}$ \\
\hline & & M1.3 collaborative innovation & $\mathrm{Q}$ \\
\hline & & M2.1 innovation investment & Q \\
\hline & M2 economic support & M2.2 investment on maintenance & Q \\
\hline & & M2.3 effective management capital & Q \\
\hline & & M3.1 evaluate climate change risks & Q \\
\hline & M3 management measure & M3.2 enhance long-term adaptation & Q \\
\hline & & M3.3 improve withstanding ability to extreme events & Q \\
\hline
\end{tabular}

Note. C, cost index; B, benefit index; Q, qualitative index. 
summarized in Table 6 . The assessment indexes of former four dimensions in Table 6 present urban infrastructure sustainability (basic quality), while the assessment indexes of measure dimension in Table 6 present urban infrastructure resilience (expanding quality).
In the assessment index system of urban infrastructure SR-GPA, qualitative indexes are quantified by the 5-point expert grading method, while quantitative indexes are quantified by the efficiency coefficient method. The quantification processes are as follows:

$$
\begin{gathered}
\text { Score of benefit index }=1+4 \times \frac{\text { actual value }- \text { forbidden value }}{\text { satisfied value }- \text { forbidden value }} \\
\text { Score of cost index }=1+4 \times \frac{\text { forbidden value }- \text { actual value }}{\text { forbidden value }- \text { satisfied value }} \text {. }
\end{gathered}
$$

Equations (4) and (5), respectively, select the highest value and the lowest value of each quantitative index as the satisfied value and forbidden value. According to the 5-point expert grading method, the basic value and the highest value of each quantitative index are 1 and 5, respectively.

3.4. ANP Structure Model of Urban Infrastructure SR-GPA. The assessment indexes set of ANP is as follows:

$$
\mathrm{U}=\left\{\mathrm{U}_{1}, \mathrm{U}_{2}, \ldots, \mathrm{U}_{k}, \ldots, \mathrm{U}_{n}\right\}, \quad k=1,2, \ldots, n,
$$

which includes first-level indexes, where $n$ represents the number of first-level indexes in set U. Each first-level index includes several second-level indexes as follows:

$$
\mathrm{U}_{k}=\left\{\mathrm{U}_{k 1}, \mathrm{U}_{k 2}, \ldots, \mathrm{U}_{k i}, \ldots, \mathrm{U}_{k n_{k}}\right\}, \quad i=1,2, \ldots, n_{k},
$$

which is a second-level indexes set, where $n_{k}$ represents the number of second-level indexes in set $\mathrm{U}_{k}$. Each second-level index includes several third-level indexes as follows:

$$
\mathrm{U}_{k i}=\left\{\mathrm{U}_{k i 1}, \mathrm{U}_{k i 2}, \ldots, \mathrm{U}_{k i j}, \ldots, \mathrm{U}_{k i n}\right\}, \quad j=1,2, \ldots, n_{k i} \text {, }
$$

which is the third-level indexes set, where $n_{k i}$ represents the number of third-level indexes in set $\mathrm{U}_{k i}$.

According to the above method, the assessment index system of urban infrastructure SR-GPA is divided into firstlevel indexes, second-level indexes, and third-level indexes. The ANP structure model of urban infrastructure SR-GPA is constructed through interaction between indexes as shown in Figure 5.

Figure 5 shows that the ANP structure model of urban infrastructure SR-GPA contains the control layer and network layer. The control layer includes goal and decision criteria. Urban infrastructure SR-GPA is the goal of the control layer, and the five dimensions and indexes are the decision criteria of the control layer. The network layer is the influence relationship between five dimensions and indexes. The ANP structure model of urban infrastructure SR-GPA considers the interaction between indexes and allocates weight to each index. Based on the quantification of indexes, the weighted synthesis model is used to calculate the comprehensive score, which describes urban infrastructure's sustainability and resilience. The basic equation of the weighted synthesis model is as follows:

$$
y=\sum_{i=1}^{m} w_{i} x_{i}
$$

where $w_{i}$ is the weight of the index, $x_{i}$ is the quantitative score, and $y$ is the final score.

\section{Case Study}

4.1. Case Background. Harbin subway is an urban transport system located in Harbin, Heilongjiang Province. It is the first subway system in the alpine region of China. The general plan of the Harbin subway has a total operation mileage of $340 \mathrm{~km}$, which includes twelve main lines, one circle line, and two branch lines. The total investment will reach 30 billion dollars, and the construction of the entire project will last for 20 years. Currently, line 1 of the Harbin subway, which includes 25 stations with a length of $27.3 \mathrm{~km}$, has been operated since September 26, 2013 [83].

This paper takes the Harbin subway as the research object (case study) because it is a typical urban infrastructure which possesses the following characteristics: high investment, long construction period, and remarkable social and economic impacts. The sustainability and resilience of the Harbin subway determine whether such mega urban infrastructure will meet the current and future needs of the city. An empirical research on the sustainability and resilience of the Harbin subway was performed by using the proposed urban infrastructure SR-GPA assessment method. We analyzed whether current sustainability and resilience status of the Harbin subway project can meet the needs of city development. Finally, problems of Harbin subway's sustainability and resilience were found, which could guide its future construction and operation.

4.2. Data Collection. The assessment indexes in Table 6 can be divided into three parts according to index properties. The assessment indexes of influence, resource, and measure dimensions reflect the sustainability and resilience of the Harbin subway from technical perspective. It is suitable that the quantitative score of these technical assessment indexes are obtained from related professional staff, such as designers, 

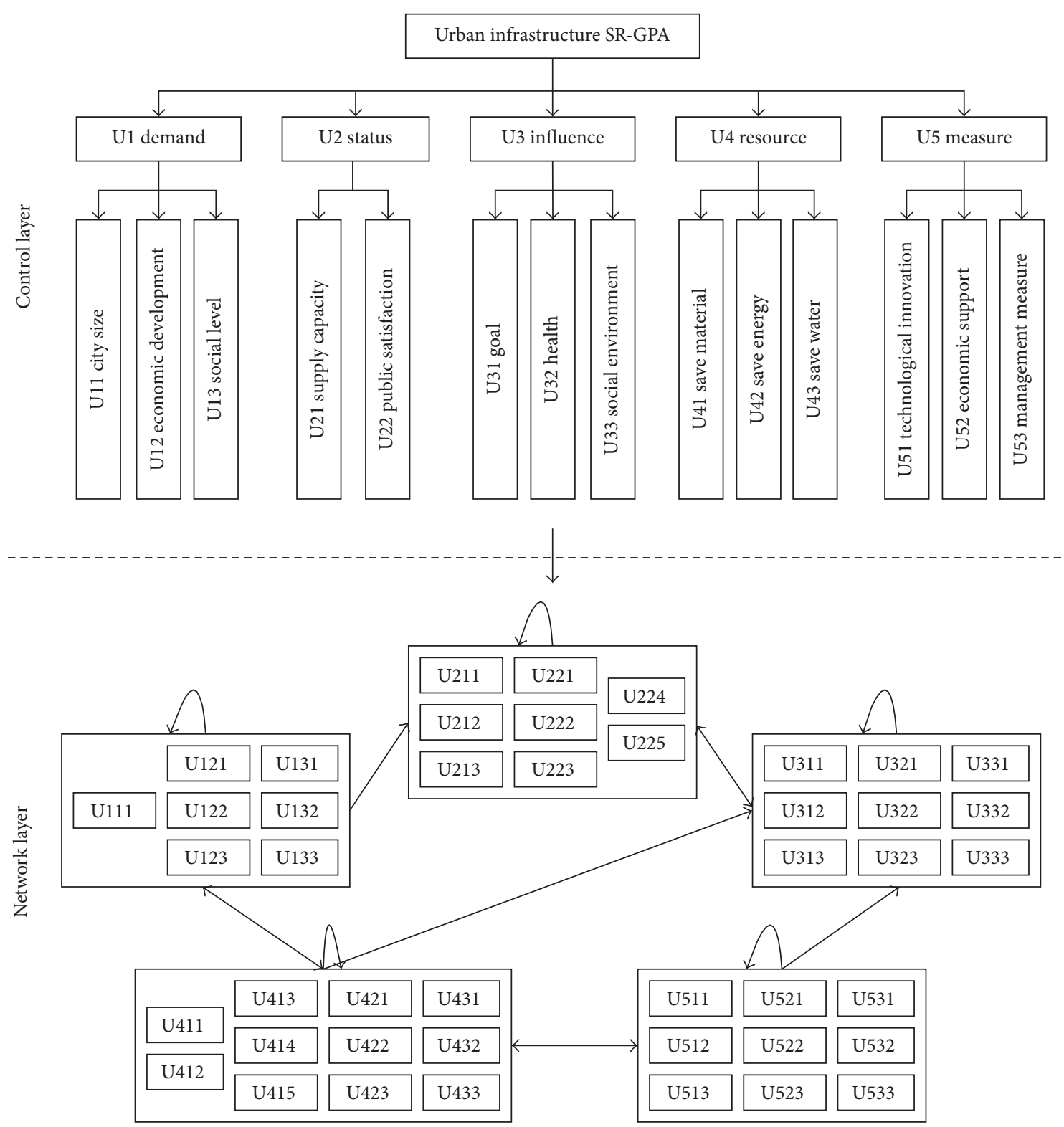

FIGURE 5: ANP structure model of urban infrastructure SR-GPA.

constructors, and operators $[25,84]$. The quantitative assessment indexes of public satisfaction in status dimension reflect the service level of the Harbin subway from the perspective of social sustainability. Thus, the quantitative score of assessment indexes in public satisfaction mainly depends on the subjective assessment of urban infrastructure users. The assessment indexes of demand dimension and supply capacity in status dimension objectively reflect the sustainability of the Harbin subway. These objective assessment indexes are closely related to the level of urban infrastructure demands [85]. Thus, the quantitative score of these objective assessment indexes are mainly obtained by comparing related indexes of cities with similar urban infrastructure demands in previous studies $[25,86]$. Through the above analysis on data collection, the data sources of the case study are summarized in Figure 6.

According to the assessment indexes of influence, resource, and measure dimensions, we select designers, constructors, and operators of the Harbin subway as respondents and collect data of qualitative indexes through questionnaires. A total of 100 questionnaires were sent out by Email with 53 valid questionnaires retrieved. Table 7 is the category distribution of respondents according to the type of work, work experience, and the number of involving projects.

According to the quantitative assessment indexes of public satisfaction in status dimension, we take passengers of the Harbin subway as respondents. A total of 400 questionnaires were sent out at stations of Harbin subway line 1 with 236 valid questionnaires retrieved. Figure 7 shows the age distribution of respondents.

According to other quantitative assessment indexes, we select fifteen major cities as samples, that is, Harbin, Hangzhou, Suzhou, Xi'an, Zhengzhou, Qingdao, Changchun, Kunming, Dalian, Changsha, Taiyuan, Jinan, Hefei, Foshan, and Urumqi. The urban resident population of the 


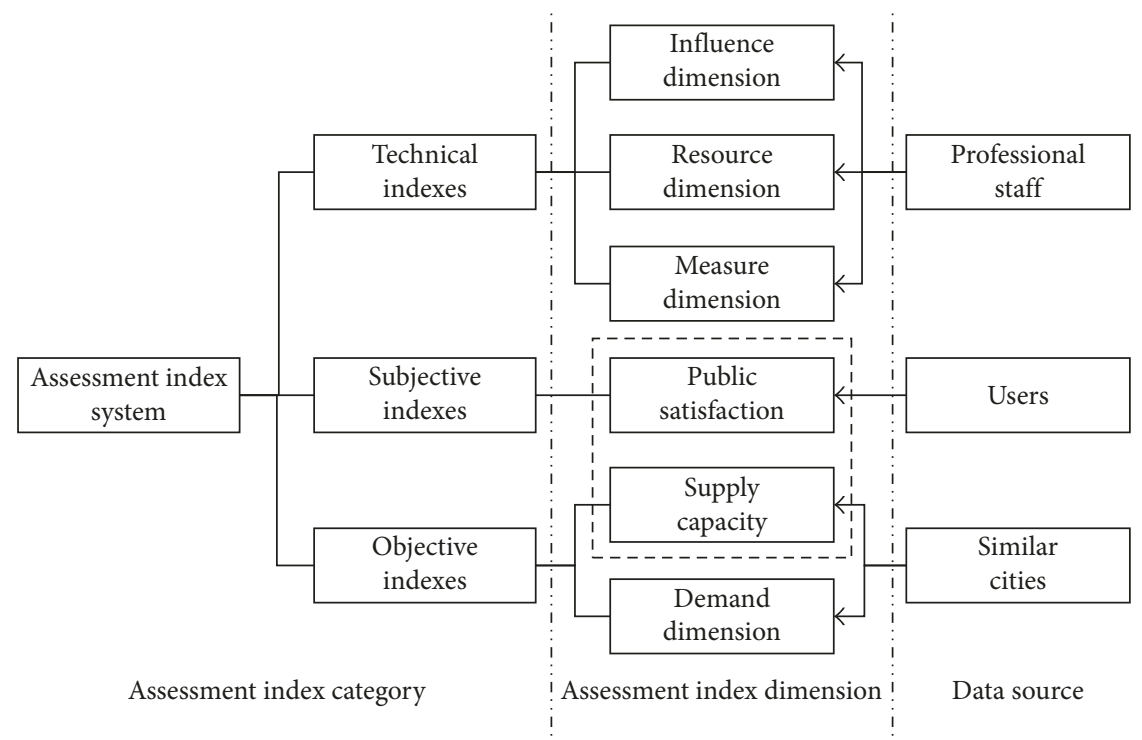

Figure 6: Data sources of the case study.

TABLE 7: Category distribution of respondents.

\begin{tabular}{|c|c|c|c|}
\hline Basis of classification & Classification criterion & Frequency & Percentage $(\%)$ \\
\hline \multirow{3}{*}{ Type of work } & Design & 11 & 20.8 \\
\hline & Construct & 25 & 47.2 \\
\hline & Operation & 17 & 32.1 \\
\hline \multirow{4}{*}{ Work experience } & Below 5 years & 7 & 13.2 \\
\hline & $6-10$ years & 11 & 20.8 \\
\hline & $11-15$ years & 14 & 26.4 \\
\hline & Above 16 years & 21 & 39.6 \\
\hline \multirow{4}{*}{ Number of involving projects } & Below 2 & 5 & 9.4 \\
\hline & $3-5$ & 11 & 20.8 \\
\hline & $6-10$ & 13 & 24.5 \\
\hline & Above 11 & 24 & 45.3 \\
\hline
\end{tabular}

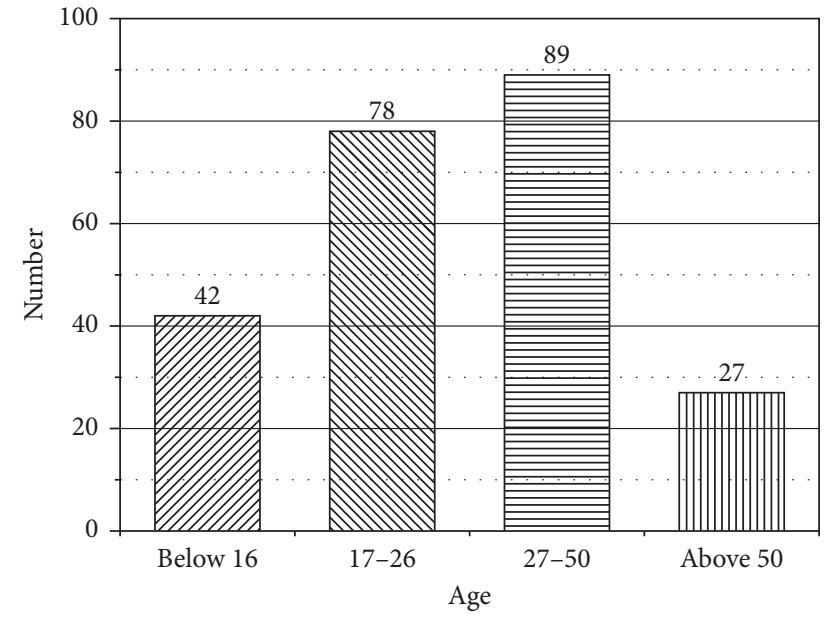

Figure 7: Age distribution of respondents.

above fifteen cities is between one million and five million, which means that these cities have similar urban infrastructure demands. The efficacy coefficient method is used to calculate the quantitative scores of quantitative indexes in demand and status dimensions.

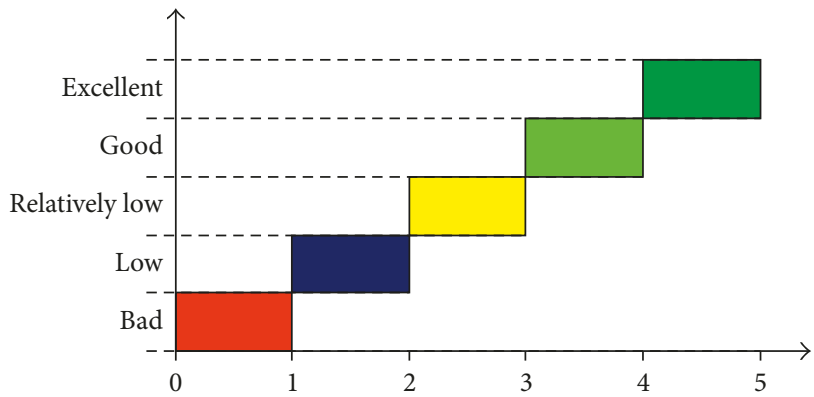

FIGURE 8: Judgment criterion of urban infrastructure SR-GPA.

\subsection{Result Analysis}

4.3.1. Index Score Analysis. In the Section 3.3.3, the assessment indexes of urban infrastructure SR-GPA are quantified by the 5 -point expert grading method. Thus, the score of each index is between 0 and 5. Through comparing existing GPA standards [87], the judgment criterion of urban infrastructure SR-GPA is summarized in Figure 8.

The horizontal axis represents the score of urban infrastructure SR-GPA, and the vertical axis represents the level 
TABLE 8: The quantitative score of assessment index.

\begin{tabular}{|c|c|c|c|}
\hline Dimension & Category & Index & Score \\
\hline \multirow{7}{*}{ Demand (D) } & D1 city size & D1.1 growth rate of city resident population & 5.00 \\
\hline & & D2.1 per capita GDP & 1.00 \\
\hline & D2 economic development & D2.2 proportion of tertiary industry in GDP & 4.16 \\
\hline & & D2.3 per capita disposable income & 1.87 \\
\hline & & D3.1 per financial income & 1.13 \\
\hline & D3 social level & D3.2 per capital expenditure & 1.39 \\
\hline & & D3.3 growth rate of infrastructure investment & 1.90 \\
\hline \multirow{8}{*}{ Status (S) } & & S1.1 handling capacity & 1.33 \\
\hline & S1 supply capacity & S1.2 infrastructure density & 1.02 \\
\hline & & S1.3 proportion of built-up area in total area & 1.47 \\
\hline & & S2.1 service quality & 4.26 \\
\hline & & S2.2 service price & 4.79 \\
\hline & S2 public satisfaction & S2.3 failure frequency & 4.84 \\
\hline & & S2.4 facility maintenance timeliness & 4.66 \\
\hline & & S2.5 facility maintenance quality & 4.81 \\
\hline \multirow{9}{*}{ Influence (I) } & & I1.1 improve community life quality & 3.40 \\
\hline & I1 goal & I1.2 stimulate sustainable development & 3.41 \\
\hline & & I1.3 develop local technology & 2.61 \\
\hline & & I2.1 improve public health and safety & 3.01 \\
\hline & I2 health & I2.2 reduce noise and vibration & 3.02 \\
\hline & & I2.3 reduce light pollution & 3.15 \\
\hline & & I3.1 protect historical and cultural resources & 4.32 \\
\hline & I3 social environment & I3.2 protect local characteristics & 4.53 \\
\hline & & I3.3 protect the environment & 2.73 \\
\hline \multirow{11}{*}{ Resource (R) } & & R1.1 reduce material usage & 1.03 \\
\hline & & R1.2 support sustainable procurement practices & 1.75 \\
\hline & R1 save material & R1.3 use renewable materials & 1.85 \\
\hline & & R1.4 use local materials & 2.45 \\
\hline & & R1.5 dispose and recycle waste & 4.03 \\
\hline & & R2.1 reduce energy consumption & 2.02 \\
\hline & R2 save energy & R2.2 use renewable energy & 1.63 \\
\hline & & R2.3 monitor the energy system & 1.25 \\
\hline & & $\mathrm{R} 3.1$ reduce water consumption & 3.22 \\
\hline & R3 save water & R3.2 reduce domestic water & 2.89 \\
\hline & & R3.3 monitor the water system & 1.05 \\
\hline \multirow{9}{*}{ Measure (M) } & & M1.1 new materials, technology, and equipment & 4.26 \\
\hline & M1 technology innovation & M1.2 intelligent monitoring system & 3.58 \\
\hline & & M1.3 collaborative innovation & 0.26 \\
\hline & & M2.1 innovation investment & 0.92 \\
\hline & M2 economic support & M2.2 investment on maintenance & 2.90 \\
\hline & & M2.3 effective management capital & 2.04 \\
\hline & & M3.1 evaluate climate change risks & 1.02 \\
\hline & M3 management measure & M3.2 enhance long-term adaptation & 0.62 \\
\hline & & M3.3 improve withstanding ability to extreme events & 2.37 \\
\hline
\end{tabular}

of urban infrastructure SR-GPA. The urban infrastructure SRGPA is divided into five levels: excellent, good, relatively low, low, and bad. Different color bars represent different score levels of assessment indexes. The above five levels correspond to five score intervals of urban infrastructure SR-GPA which are 4 to 5,3 to 4,2 to 3,1 to 2 , and 0 to 1 .

According to the quantitative methods of urban infrastructure SR-GPA, we quantitate the data of assessment indexes and calculate the quantitative scores of indexes in the Harbin subway SR-GPA assessment index system. The quantitative scores of assessment indexes are shown in Table 8.

Table 8 summarizes the score level of each index from five dimensions, and the analysis results are as follows:
(1) Demand Dimension. The score of index D1.1 is 5, which means that the level of D1 city size is excellent. The score of index D1.1 also reflects that the Harbin subway can satisfy the growth demand of city resident population. The level of the score of most indexes in D2 economic development and D3 social level is low. These reflect that Harbin has a disadvantage on sustainable development level compared with cities of similar scale. The low-speed urban expansion of Harbin results in less pressure on the investment of Harbin subway.

(2) Status Dimension. The supply capacity of the Harbin subway is low, which is reflected by the low score of handling 
capacity, infrastructure density, and proportion of built-up area in total area, while the score of index of public satisfaction is good, which reflects the public is satisfied with the service of Harbin subway. The results meet the real situation that Harbin subway is just put into use and only operates line 1 currently.

(3) Influence Dimension. From the perspective of I1 goal, the Harbin subway plays a positive role in improving people's quality of life and promoting sustainable economic and social development. The Harbin subway takes measures to reduce the light pollution, noise and vibration, and other negative effects in the construction process, and the scores of indexes in I2 health are good. The construction of the Harbin subway has realized the organic combination with the social environment and historical development. Harbin's humanistic environment is consciously protected, which strengthen cultural heritage and public identity. It is particularly prominent that the Harbin subway can protect historical and cultural resources. The average score of indexes in I3 social environment is excellent. In general, the Harbin subway has positive influence on the sustainable development of Harbin.

(4) Resource Dimension. The scores of most indexes in R1 save material are low, which indicates that the Harbin subway lacks the assessment of total materials energy consumption in the process of construction and operation from the perspective of life cycle. The Harbin subway is more inclined to use local materials and focuses on waste disposal and recycling. The score of support sustainable procurement practices and use renewable materials are low. The Harbin subway has poor performance of saving energy, which is reflected by the low or relatively low score of reducing energy consumption, using renewable energy and energy monitor system. The construction of the Harbin subway has involved great efforts in water saving, which is reflected by the good score of R3.1 reduce water consumption.

(5) Measure Dimension. The Harbin subway focuses on the application of new materials, technologies, and equipment in the process of construction and operation. The intelligent detection system is used to monitor the operation situation of Harbin subway. Thus, the scores of indexes in M1.1 new materials, technology, and equipment and M1.2 intelligent monitoring system are excellent and good. The bad score of M1.3 collaborative innovation reflects that new technologies should be implicated by innovation investment and collaborative innovation among enterprises, universities, and research institutions. The scores of indexes in M2 economic support and M3 management measure are below good level, which means that the Harbin subway should take economic and management measures to enhance long-term resilience and emphasize on monitoring responding to extreme events in the operational phase.

4.3.2. Measuring Result Analysis. According to the ANP structure model of urban infrastructure SR-GPA, the calculation result of weight is summarized in Table 9.
Table 9 shows that the weights of different indexes have great differences. The weights of influence and measure dimension are relatively large, which indicates that these indexes are crucial in improving urban infrastructure SRGPA. The weights of demand dimension are relatively small, which indicates that urban development level has small impacts on urban infrastructure SR-GPA. Combined with quantitative scores and ultimate limit weight, the final scores of indexes are summarized from five dimensions and fourteen categories (Table 10).

Table 10 shows final score levels of indexes from different dimensions and categories. According to the judgment criterion of urban infrastructure SR-GPA, the score of City size is excellent, which means that the Harbin subway can satisfy the growth demand of city resident population and the construction of the Harbin subway does not exert excessive pressure. Considering long-term development of Harbin, the scores of Economic development and Social level are low, and Harbin subway cannot meet the long-term demands of urban sustainable development. From the perspectives of status and influence dimensions, the scores of these two dimensions are good. The Harbin subway improves people's living standards and promotes economic and social development of the city. From the perspective of resource dimension, the Harbin subway lacks practical measures on saving material, energy, and water. Thus, the score of resource dimension is low. From the perspective of measure dimension, the Harbin subway does not consider technical, economic, and management measures systematically, and its resilience is not considered in the whole life cycle.

Overall, the Harbin subway SR-GPA is 2.6277 , which is a relatively low level. The Harbin subway SR-GPA can be upgraded by improving assessment indexes which have relatively low, low, and bad level scores. According to Table 10, these assessment indexes are focus on demand dimension, supply capacity in status dimension, resource dimension and measure dimension. The Harbin subway SR-GPA should be enhanced using the following three aspects:

(1) The supply capacity of the Harbin subway should be improved by increasing the construction investment: cities have different demands for infrastructure, and the size of cities should be matched with the demands of infrastructure. Harbin's economic and social development indexes are in low levels. More infrastructures are required to ensure the expansion of urban scale, economic development, and social progress. To promote sustainable development, Harbin should increase the investment in subway construction and ensure the effective use of construction funds. A complete network of the Harbin subway enhances the supply capacity of the Harbin subway, which can meet the needs of sustainable development.

(2) In the process of construction and operation, the Harbin subway should efficiently allocate resources and implement sustainable development practices: the scores of assessment indexes in resource dimension are all below good level. The construction and operation of infrastructure cannot avoid the 
TABLE 9: The ultimate limit weight of assessment index.

\begin{tabular}{|c|c|c|c|}
\hline Dimension & Category & Index & Weight \\
\hline \multirow{7}{*}{ Demand (D) } & D1 city size & D1.1 growth rate of city resident population & 0.00132 \\
\hline & & D2.1 per capita GDP & 0.00402 \\
\hline & D2 economic development & D2.2 proportion of tertiary industry in GDP & 0.00142 \\
\hline & & D2.3 per capita disposable income & 0.00191 \\
\hline & & D3.1 per financial income & 0.00148 \\
\hline & D3 social level & D3.2 per capital expenditure & 0.00404 \\
\hline & & D3.3 growth rate of infrastructure investment & 0.00587 \\
\hline \multirow{8}{*}{ Status (S) } & & S1.1 handling capacity & 0.00146 \\
\hline & S1 supply capacity & S1.2 infrastructure density & 0.00652 \\
\hline & & S1.3 proportion of built-up area in total area & 0.00774 \\
\hline & & S2.1 service quality & 0.01453 \\
\hline & & S2.2 service price & 0.00018 \\
\hline & S2 public satisfaction & S2.3 failure frequency & 0.00209 \\
\hline & & S2.4 facility maintenance timeliness & 0.00963 \\
\hline & & S2.5 facility maintenance quality & 0.00994 \\
\hline \multirow{9}{*}{ Influence (I) } & & I1.1 improve community life quality & 0.07062 \\
\hline & I1 goal & I1.2 stimulate sustainable development & 0.06409 \\
\hline & & I1.3 develop local technology & 0.06313 \\
\hline & & I2.1 improve public health and safety & 0.05791 \\
\hline & I2 health & I2.2 reduce noise and vibration & 0.02279 \\
\hline & & I2.3 reduce light pollution & 0.01972 \\
\hline & & I3.1 protect historical and cultural resources & 0.02714 \\
\hline & I3 social environment & I3.2 protect local characteristics & 0.03264 \\
\hline & & I3.3 protect the environment & 0.03515 \\
\hline \multirow{11}{*}{ Resource (R) } & & R1.1 reduce material usage & 0.03137 \\
\hline & & R1.2 support sustainable procurement practices & 0.03076 \\
\hline & $\mathrm{R} 1$ save material & $\mathrm{R} 1.3$ use renewable materials & 0.02466 \\
\hline & & R1.4 use local materials & 0.02109 \\
\hline & & R1.5 dispose and recycle waste & 0.02024 \\
\hline & & R2.1 reduce energy consumption & 0.03113 \\
\hline & R2 save energy & R2.2 use renewable energy & 0.02923 \\
\hline & & $\mathrm{R} 2.3$ monitor the energy system & 0.02246 \\
\hline & & $\mathrm{R} 3.1$ reduce water consumption & 0.03008 \\
\hline & R3 save water & R3.2 reduce domestic water & 0.02876 \\
\hline & & R3.3 monitor the water system & 0.01818 \\
\hline \multirow{9}{*}{ Measure (M) } & & M1.1 new materials, technology, and equipment & 0.03933 \\
\hline & M1 technology innovation & M1.2 intelligent monitoring system & 0.01916 \\
\hline & & M1.3 collaborative innovation & 0.01579 \\
\hline & & M2.1 innovation investment & 0.03168 \\
\hline & M2 economic support & M2.2 investment on maintenance & 0.03292 \\
\hline & & M2.3 effective management capital & 0.02027 \\
\hline & & M3.1 evaluate climate change risks & 0.01844 \\
\hline & M3 management measure & M3.2 enhance long-term adaptation & 0.02675 \\
\hline & & M3.3 improve withstanding ability to extreme events & 0.02936 \\
\hline
\end{tabular}

consumption of resources; the efficiency of resources utilization has direct impacts on the sustainability of infrastructure. The construction of the Harbin subway lacks clear advantages in resources utilization and shows disadvantages in using renewable materials and energy. To improve the sustainability of the Harbin subway, it is necessary to allocate resources rationally and comprehensively from the aspects of saving material, energy, and water.

(3) The consumption of materials, energy, and water should be assessed from the perspective of whole life cycle, and the construction of the Harbin subway should find ways to reduce resource consumption. The
Harbin subway should choose suppliers who consider economic, social, and environmental impacts in the process of production and select suppliers with good reputation and ethical responsibility. In addition to these measures, the monitoring system should be used to monitor material consumption, energy use, and water consumption. All the above measures can improve the scores of assessment indexes in resource dimension.

(4) The resilience of the Harbin subway should be improved by economic support and management measure: the resilience of infrastructure reflects its adaptive ability to changing conditions in the long term as well 
TABLE 10: The quantitative score of SR-GPA.

\begin{tabular}{|c|c|c|c|}
\hline Goal & Dimension & Category & Score \\
\hline \multirow{14}{*}{ Harbin subway SR-GPA (2.6277) } & \multirow{3}{*}{ Demand (1.9212) } & City size & 5 \\
\hline & & Economic development & 1.8366 \\
\hline & & Social level & 1.6191 \\
\hline & \multirow{2}{*}{ Status (3.5618) } & Supply capacity & 1.2704 \\
\hline & & Public satisfaction & 4.5522 \\
\hline & \multirow{3}{*}{ Influence (3.1222) } & Goal & 3.1512 \\
\hline & & Health & 2.4212 \\
\hline & & Social environment & 3.8035 \\
\hline & \multirow{3}{*}{ Resource (2.0928) } & Save material & 2.0684 \\
\hline & & Save energy & 1.6735 \\
\hline & & Save water & 2.5846 \\
\hline & \multirow{3}{*}{ Measure (1.5612) } & Technology innovation & 3.2343 \\
\hline & & Economic support & 1.4683 \\
\hline & & Management measure & 0.4748 \\
\hline
\end{tabular}

as its rapid recovery capabilities in emergency situations. The resilience of infrastructure should be considered in whole life cycle including the optimization of structural design and the use of new materials, technologies, and equipment. The risks should be comprehensively assessed to enhance infrastructure's long-term adaptive capacity and quick response capacity in case of unexpected conditions. The Harbin subway applied the advanced monitoring system in the operation process and shows good response ability to unexpected situations.

(5) The score of the Harbin subway economic support index is low, and the score of Harbin subway management measure index is even bad. Thus, the resilience of the Harbin subway should also be improved by strengthening management in design and construction phases. During the design phase, cooperation between enterprises, universities, research institutions, and other organizations should be strengthened to promote technological innovation and design optimization, therefore improving the resilience of the Harbin subway. The Harbin subway should sustain a series of changes in natural conditions, such as temperature changes, precipitation, and seasonal hydrological conditions. The decentralized system should be designed to make the Harbin subway maintain a certain function even if some components are damaged. During the construction phase, the Harbin subway should monitor climate changes, the emergence of extreme weather, and other natural disasters. Emergency plan should be developed in advance to improve the response and recovery speed of the Harbin subway to extreme events.

\section{Discussion}

Sustainability and resilience have different origins and evolve separately in theory and practice. Due to the different origins, the definitions of sustainability and resilience present significant differences [41]. The sustainability assessment of urban infrastructure mostly depends on different quantitative and qualitative indicators, while the resilience assessment of urban infrastructure usually focuses on quantified equation [42, 43]. Urban infrastructure sustainability and resilience are separated in most previous studies.

Urban infrastructure sustainability assessment only analyzes the regular performances of urban infrastructure from different sustainable perspectives in normal status [57]. These assessment methods of urban infrastructure sustainability are ineffective to improve urban infrastructure performance under extreme events [25]. Urban infrastructure resilience assessment mainly analyzes the responses of urban infrastructure due to extreme events and the ability of recovery under these circumstances [58]. The status of urban infrastructure is designed at a high level to satisfy the needs of urban infrastructure resilience, which has negative impacts on urban infrastructure sustainable development in normal status $[59,60]$. Thus, the sustainability and resilience of urban infrastructure should be considered and assessed together [56].

Previous studies have attempted to combine these two concepts for assessment [47]. Some conceptual descriptions are used to combine some specific properties of resilience into urban infrastructure sustainability [12, 49, 50]. More and more urban infrastructure sustainability assessment approaches cover risk-associated climate change, even though no further hazard-related consequences are addressed [53, 54]. Previous studies also incorporated the properties of sustainability in infrastructure resilience analysis [55]. Urban infrastructure resilience is mainly assessed from the environment and economic perspectives of sustainability [47]. Thus, previous studies did not really combine urban infrastructure sustainability and resilience. Urban infrastructure resilience is considered as the branch of urban infrastructure sustainability under extreme events. Urban infrastructure sustainability is selected as the goals of urban infrastructure resilience. Urban infrastructure sustainability and resilience are essentially two separate concepts on previous studies.

This study proposed a new unified assessment approach for urban infrastructure sustainability and resilience using the concept of urban infrastructure SR-GPA. The GPA of 
urban infrastructure's sustainability and resilience (urban infrastructure SR-GPA) is proposed as a unified concept. The assessment index system of urban infrastructure SRGPA is constructed from five dimensions including demand, status, influence, resource, and measure. The analytic network process (ANP) is used to assess urban infrastructure SR-GPA considering the interaction between the indexes. The ANP structure model of urban infrastructure SR-GPA is established based on the assessment method and index system. This new assessment approach bridged the above gaps that the sustainability and resilience of urban infrastructure were separated on existing researches. This study provided strong supports for academic and industrial fields to assess, analyze, enhance, and optimize the sustainability and resilience of urban infrastructure together.

\section{Conclusions}

This paper systematically reviewed previous studies of urban infrastructure's sustainability and resilience. To mutually assess the sustainability and resilience of urban infrastructure, the paper proposed the concept of urban infrastructure SR-GPA and constructed the urban infrastructure SR-GPA assessment index system and ANP structure model. Taking the Harbin subway as the research object, the Harbin subway SR-GPA was assessed and analyzed, with promotion strategies proposed to improve Harbin subway's sustainability and resilience.

The main achievements of this study are as follows: (1) proposing the concept of urban infrastructure SR-GPA: analyzed the research status of urban infrastructure sustainability and resilience, integrated the concepts of sustainability and resilience into urban infrastructure GPA assessment, and defined the concept of urban infrastructure SR-GPA; (2) constructing the urban infrastructure SR-GPA assessment index system and ANP structure model: from demand, status, influence, resources, and measures dimensions, the built urban infrastructure SR-GPA assessment index system calculated the quantitative scores of qualitative and quantitative indexes, respectively, through questionnaires and the efficiency coefficient method, and formed the ANP structure model to assess urban infrastructure SR-GPA; and (3) assessing the Harbin subway SR-GPA: calculated quantitative scores and ultimate limit weight of indexes in the Harbin subway SR-GPA assessment index system, analyzed the Harbin subway SRGPA status, and proposed promotion strategies to improve the sustainability and resilience of Harbin subway.

Further conclusions can be drawn as follows: (1) sustainability and resilience are two important properties of urban infrastructure. Although these two concepts have different origins and independent developing routes in urban infrastructure, they share common connotations that are mainly reflected through research perspective, dimensions, methods, and goals. The concepts of sustainability and resilience should be integrated to provide a comprehensive assessment of urban infrastructure's property. (2) The biggest challenge for assessing properties of urban infrastructure's sustainability and resilience is how to combine the two concepts. Urban infrastructure SR-GPA is a new conceptual attempt to provide a unified perspective of urban infrastructure's sustainability and resilience. Urban infrastructure SR-GPA can be divided into basic quality and expanding quality, which reflect urban infrastructure's sustainability and resilience, respectively. (3) The assessment of urban infrastructure SR-GPA involves multiple dimensions and indexes, which constitute the assessment index system of urban infrastructure SR-GPA. The interactions of different dimensions and indexes should be considered in the assessment process, and ANP is a reasonable choice which can solve the above problem through the construction of the ANP structure model. (4) The empirical study of the Harbin subway shows that the proposed method can locate dimensions that are important for improving urban infrastructure SR-GPA. The weights of influence and measure dimension are relatively large. These indexes should be focused in the process of improving urban infrastructure SR-GPA. The weights of demand dimension are relatively small, which reflects that urban development level has small impacts on urban infrastructure SR-GPA. (5) The Harbin subway SR-GPA is in a relatively low level and needs to be upgraded through increasing construction investment, allocating resources efficiently and considering resilience in whole life cycle. The assessment results of the Harbin subway SR-GPA can be used to guide the future construction and operation of the Harbin subway.

Future works can be done to improve the assessment index system of urban infrastructure SR-GPA. More indexes should be selected and added to reflect the resilience of urban infrastructure. The automatic assessment system of urban infrastructure SR-GPA can be developed to provide the real-time data of urban infrastructure SR-GPA.

\section{Data Availability}

The data used to support the findings of this study are available from the corresponding author upon request.

\section{Conflicts of Interest}

The authors declare that they have no conflicts of interest.

\section{Acknowledgments}

This research was supported by the National Natural Science Foundation of China (NSFC) (nos. 71390522, 71671053, 71271065, and 71771067). The work described in this paper was also funded by the National Key R\&D Program of China (nos. 2016YFC0701800 and 2016YFC0701808).

\section{References}

[1] L. M. A. Bettencourt, J. Lobo, D. Helbing, C. Kuhnert, and G. B. West, "Growth, innovation, scaling, and the pace of life in cities," Proceedings of the National Academy of Sciences, vol. 104, no. 17, pp. 7301-7306, 2007.

[2] P. Crane and A. Kinzig, "Nature in the metropolis," Science, vol. 308, no. 5726, p. 1225, 2005.

[3] M. Gandy, "Cyborg urbanization: complexity and monstrosity in the contemporary city," International Journal of Urban and Regional Research, vol. 29, no. 1, pp. 26-49, 2005. 
[4] J. Atack, F. Bateman, M. Haines, and R. A. Margo, "Did railroads induce or follow economic growth?," Social Science History, vol. 34, no. 2, pp. 171-197, 2010.

[5] B. Liddle, "Impact of population, age structure, and urbanization on carbon emissions/energy consumption: evidence from macro-level, cross-country analyses," Population and Environment, vol. 35, no. 3, pp. 286-304, 2014.

[6] L. Seeliger and I. Turok, "Towards sustainable cities: extending resilience with insights from vulnerability and transition theory," Sustainability, vol. 5, no. 5, pp. 2108-2128, 2013.

[7] M. Acuto, S. Parnell, and K. Seto, "Building a global urban science," Nature Sustainability, vol. 1, no. 1, pp. 2-4, 2018.

[8] N. O. Attoh-Okine, A. T. Cooper, and S. A. Mensah, "Formulation of resilience index of urban infrastructure using belief functions," IEEE Systems Journal, vol. 3, no. 2, pp. 147-153, 2009.

[9] U. Berardi, "Sustainability assessment in the construction sector: rating systems and rated buildings," Sustainable Development, vol. 20, no. 6, pp. 411-424, 2012.

[10] W. L. Lee, "Benchmarking energy use of building environmental assessment schemes," Energy and Buildings, vol. 45, pp. 326-334, 2012.

[11] H. Yao, L. Shen, Y. Tan, and J. Hao, "Simulating the impacts of policy scenarios on the sustainability performance of infrastructure projects," Automation in Construction, vol. 20, no. 8, pp. 1060-1069, 2011.

[12] P. Bocchini, D. M. Frangopol, T. Ummenhofer, and T. Zinke, "Resilience and sustainability of civil infrastructure: toward a unified approach," Journal of Infrastructure Systems, vol. 20, no. 2, article 04014004, 2013.

[13] H. Zhou, J. Wan, and H. Jia, "Resilience to natural hazards: a geographic perspective," Natural Hazards, vol. 53, no. 1, pp. 21-41, 2010.

[14] M. Bruneau, S. E. Chang, R. T. Eguchi et al., "A framework to quantitatively assess and enhance the seismic resilience of communities," Earthquake Spectra, vol. 19, no. 4, pp. 733-752, 2003.

[15] P. Glavič and R. Lukman, "Review of sustainability terms and their definitions," Journal of Cleaner Production, vol. 15, no. 18, pp. 1875-1885, 2007.

[16] T. McDaniels, S. Chang, D. Cole et al., "Fostering resilience to extreme events within infrastructure systems: characterizing decision contexts for mitigation and adaptation," Global Environmental Change, vol. 18, no. 2, pp. 310-318, 2008.

[17] S. Lélé and R. B. Norgaard, "Sustainability and the scientist's burden," Conservation Biology, vol. 10, no. 2, pp. 354-365, 1996.

[18] E. Ostrom, J. Burger, C. B. Field, R. B. Norgaard, and D. Policansky, "Revisiting the commons: local lessons, global challenges," Science, vol. 284, no. 5412, pp. 278-282, 1999.

[19] P. Marcuse, "Sustainability is not enough," Environment and Urbanization, vol. 10, no. 2, pp. 103-112, 1998.

[20] Y. Kajikawa, "Research core and framework of sustainability science," Sustainability Science, vol. 3, no. 2, pp. 215-239, 2008.

[21] B. J. Brown, M. E. Hanson, D. M. Liverman, and R. W. Merideth, "Global sustainability: toward definition," Environmental Management, vol. 11, no. 6, pp. 713-719, 1987.

[22] G. John, D. Clements-Croome, and G. Jeronimidis, "Sustainable building solutions: a review of lessons from the natural world," Building and Environment, vol. 40, no. 3, pp. 319-328, 2005.

[23] A. Haapio and P. Viitaniemi, "A critical review of building environmental assessment tools," Environmental Impact Assessment Review, vol. 28, no. 7, pp. 469-482, 2008.
[24] T. Litman and D. Burwell, "Issues in sustainable transportation," International Journal of Global Environmental Issues, vol. 6, no. 4, pp. 331-347, 2006.

[25] H. R. Sahely, C. A. Kennedy, and B. J. Adams, "Developing sustainability criteria for urban infrastructure systems," Canadian Journal of Civil Engineering, vol. 32, no. 1, pp. 72-85, 2005.

[26] S. Dasgupta and E. K. L. Tam, "Indicators and framework for assessing sustainable infrastructure," Canadian Journal of Civil Engineering, vol. 32, no. 1, pp. 30-44, 2005.

[27] G. Schiller, "Urban infrastructure: challenges for resource efficiency in the building stock," Building Research and Information, vol. 35, no. 4, pp. 399-411, 2007.

[28] T. Yigitcanlar and F. Dur, "Developing a sustainability assessment model: the sustainable infrastructure, land-use, environment and transport model," Sustainability, vol. 2, no. 1 , pp. 321-340, 2010.

[29] M. A. Rijsberman and F. H. M. Van De Ven, "Different approaches to assessment of design and management of sustainable urban water systems," Environmental Impact Assessment Review, vol. 20, no. 3, pp. 333-345, 2000.

[30] A. J. Balkema, H. A. Preisig, R. Otterpohl, and F. J. D. Lambert, "Indicators for the sustainability assessment of wastewater treatment systems," Urban Water, vol. 4, no. 2, pp. 153-161, 2002.

[31] N. H. Afgan and M. G. Carvalho, "Sustainability assessment of hydrogen energy systems," International Journal of Hydrogen Energy, vol. 29, no. 13, pp. 1327-1342, 2004.

[32] C. Mihyeon Jeon and A. Amekudzi, "Addressing sustainability in transportation systems: definitions, indicators, and metrics," Journal of Infrastructure Systems, vol. 11, no. 1, pp. 31-50, 2005.

[33] C. S. Holling, "Resilience and stability of ecological systems," Annual Review of Ecology and Systematics, vol. 4, no. 1, pp. 1-23, 1973.

[34] A. Rose, "Economic resilience to natural and man-made disasters: multidisciplinary origins and contextual dimensions," Environmental Hazards, vol. 7, no. 4, pp. 383-398, 2007.

[35] S. E. Chang, "Evaluating disaster mitigations: methodology for urban infrastructure systems," Natural Hazards Review, vol. 4, no. 4, pp. 186-196, 2003.

[36] M. Bruneau and A. Reinhorn, "Exploring the concept of seismic resilience for acute care facilities," Earthquake Spectra, vol. 23, no. 1, pp. 41-62, 2007.

[37] S. E. Chang and M. Shinozuka, "Measuring improvements in the disaster resilience of communities," Earthquake Spectra, vol. 20, no. 3, pp. 739-755, 2004.

[38] D. A. Reed, K. C. Kapur, and R. D. Christie, "Methodology for assessing the resilience of networked infrastructure," IEEE Systems Journal, vol. 3, no. 2, pp. 174-180, 2009.

[39] E. D. Vugrin, D. E. Warren, and M. A. Ehlen, "A resilience assessment framework for infrastructure and economic systems: quantitative and qualitative resilience analysis of petrochemical supply chains to a hurricane," Process Safety Progress, vol. 30, no. 3, pp. 280-290, 2011.

[40] C. W. Zobel, "Representing perceived tradeoffs in defining disaster resilience," Decision Support Systems, vol. 50, no. 2, pp. 394-403, 2011.

[41] R. E. Ulanowicz, S. J. Goerner, B. Lietaer, and R. Gomez, "Quantifying sustainability: resilience, efficiency and the return of information theory," Ecological Complexity, vol. 6, no. 1, pp. 27-36, 2009.

[42] R. K. Singh, H. R. Murty, S. K. Gupta, and A. K. Dikshit, "An overview of sustainability assessment methodologies," Ecological Indicators, vol. 9, no. 2, pp. 189-212, 2009. 
[43] S. Hosseini, K. Barker, and J. E. Ramirez-Marquez, "A review of definitions and measures of system resilience," Reliability Engineering and System Safety, vol. 145, pp. 47-61, 2016.

[44] W. N. Adger, "Social and ecological resilience: are they related?," Progress in Human Geography, vol. 24, no. 3, pp. 347-364, 2000.

[45] K. Magis, "Community resilience: an indicator of social sustainability," Society and Natural Resources, vol. 23, no. 5, pp. 401-416, 2010.

[46] J. Anderies, C. Folke, B. Walker, and E. Ostrom, “Aligning key concepts for global change policy: robustness, resilience, and sustainability," Ecology and Society, vol. 18, no. 2, p. 8, 2013.

[47] A. Rose, "Resilience and sustainability in the face of disasters," Environmental Innovation and Societal Transitions, vol. 1, no. 1, pp. 96-100, 2011.

[48] T. Zinke, P. Bocchini, D. M. Frangopol, and T. Ummenhofer, "Combining resilience and sustainability in infrastructure projects," in Proceedings of the Third International Symposium on Life-Cycle Civil Engineering, pp. 3-6, Vienna, Austria, October 2012.

[49] B. L. Turner, "Vulnerability and resilience: coalescing or paralleling approaches for sustainability science?," Global Environmental Change, vol. 20, no. 4, pp. 570-576, 2010.

[50] A. Amantini, M. Choraś, S. D’Antonio, E. Egozcue, D. Germanus, and R. Hutter, "The human role in tools for improving robustness and resilience of critical infrastructures," Cognition Technology and Work, vol. 14, no. 2, pp. 143-155, 2012.

[51] CEEQUAL, Scheme Description and Assessment Process Handbook Version 5, February 2018, http://www.ceequal. com/downloads/.

[52] Institute for Sustainable Infrastructure (ISI), Draft of the Envision Assessment System, Version 3.0, February 2018, http://www.sustainableinfrastructure.org/.

[53] L. Larsen, L. Nicholas, C. Leighton et al., Green Building and Climate Resilience: Understanding Impacts and Preparing for Changing Conditions, University of Michigan, Ann Arbor, MI, USA, 2011.

[54] National Research Council (NRC), Sustainable Critical Infrastructure Systems-A Framework for Meeting 21st-Century Imperatives, National Research Council, National Academies Press, Washington, DC, USA, 2009.

[55] J. Ghosh, C. Tapia, and J. E. Padgett, "Life-cycle analysis of embodied energy for aging bridges subject to seismic hazards," in Applications of Statistics and Probability in Civil Engineering, M. Faber, J. Köhler, and K. Nishijima, Eds., CRC Press, Boca Raton, FL, USA, 2008.

[56] A. Milman and A. Short, "Incorporating resilience into sustainability indicators: an example for the urban water sector," Global Environmental Change, vol. 18, no. 4, pp. 758-767, 2008.

[57] C. Nelms, A. D. Russell, and B. J. Lence, "Assessing the performance of sustainable technologies for building projects," Canadian Journal of Civil Engineering, vol. 32, no. 1, pp. 114-128, 2005.

[58] R. Francis and B. Bekera, "A metric and frameworks for resilience analysis of engineered and infrastructure systems," Reliability Engineering and System Safety, vol. 121, pp. 90-103, 2014.

[59] J. A. Wardekker, A. de Jong, J. M. Knoop, and J. P. van der Sluijs, "Operationalising a resilience approach to adapting an urban delta to uncertain climate changes," Technological Forecasting and Social Change, vol. 77, no. 6, pp. 987-998, 2010.
[60] P. Bolund and S. Hunhammar, "Ecosystem services in urban areas," Ecological Economics, vol. 29, no. 2, pp. 293-301, 1999.

[61] M. Cavallaro, D. Asprone, V. Latora, G. Manfredi, and V. Nicosia, "Assessment of urban ecosystem resilience through hybrid social-physical complex networks," Computer-Aided Civil and Infrastructure Engineering, vol. 29, pp. 608-625, 2014.

[62] J. R. Pack and A. Altshuler, "Fragile foundations: a report on America's public works, national council on public works improvement," Journal of Policy Analysis and Management, vol. 8, pp. 505-508, 1989.

[63] L. M. Meade and J. Sarkis, “Analyzing organizational project alternatives for agile manufacturing processes: an analytical network approach," International Journal of Production Research, vol. 37, no. 2, pp. 241-261, 1999.

[64] C. N. Huang, J. H. Liou, and Y. C. Chuang, "A method for exploring the interdependencies and importance of critical infrastructures," Knowledge-Based Systems, vol. 55, pp. 66-74, 2014.

[65] T. L. Saaty, "Priority setting in complex problems," IEEE Transactions on Engineering Management, vol. 209, no. 3, pp. 140-155, 1983.

[66] L. M. Meade and A. Presley, "R\&D project selection using the analytic network process," IEEE Transactions on Engineering Management, vol. 49, no. 1, pp. 59-66, 2002.

[67] Z. Ayağ and R. G. Özdemir, "A hybrid approach to concept selection through fuzzy analytic network process," Computers and Industrial Engineering, vol. 56, no. 1, pp. 368-379, 2009.

[68] M. Ouyang, L. Dueñas-Osorio, and X. Min, "A three-stage resilience analysis framework for urban infrastructure systems," Structural Safety, vol. 36, pp. 23-31, 2012.

[69] M. Sohail, S. Cavill, and A. P. Cotton, "Sustainable operation and maintenance of urban infrastructure: myth or reality?" Journal of urban planning and development, vol. 131, no. 1, pp. 39-49, 2005.

[70] L. F. Gay and S. K. Sinha, "Resilience of civil infrastructure systems: literature review for improved asset management," International Journal of Critical Infrastructures, vol. 9, no. 4, pp. 330-350, 2013.

[71] O. Ugwu and T. C. Haupt, "Key performance indicators and assessment methods for infrastructure sustainability - a South African construction industry perspective," Building and Environment, vol. 42, no. 2, pp. 665-680, 2007.

[72] Department of Urban Surveys, National Bureau of Statistics of China, China City Statistical Yearbook-2014, China Statistics Press, Beijing, China, 2014, in Chinese.

[73] Department of Urban Surveys, National Bureau of Statistics of China, China Environment Statistical Yearbook-2014, China Statistics Press, Beijing, China, 2014, in Chinese.

[74] S. Cloutier, J. Jambeck, and N. Scott, "The sustainable neighborhoods for happiness index (SNHI): a metric for assessing a community's sustainability and potential influence on happiness," Ecological Indicators, vol. 40, pp. 147-152, 2014.

[75] J. M. Fischer and A. Amekudzi, "Quality of life, sustainable civil infrastructure, and sustainable development: strategically expanding choice," Journal of Urban Planning and Development, vol. 137, no. 1, pp. 39-48, 2011.

[76] M. Jovanovic, N. Afgan, and V. Bakic, "An analytical method for the measurement of energy system sustainability in urban areas," Energy, vol. 35, no. 9, pp. 3909-3920, 2010.

[77] B. V. Reddy and K. S. Jagadish, "Embodied energy of common and alternative building materials and technologies," Energy and Buildings, vol. 35, no. 2, pp. 129-137, 2003. 
[78] M. Calkins, Materials for Sustainable Sites: A Complete Guide to the Evaluation, Selection, and Use of Sustainable Construction Materials, John Wiley \& Sons, New York, NY, USA, 2008.

[79] F. Martin-Carrasco, L. Garrote, A. Iglesias, and L. Mediero, "Diagnosing causes of water scarcity in complex water resources systems and identifying risk management actions," Water Resources Management, vol. 27, no. 6, pp. 1693-1705, 2013.

[80] B. Cohen, "Urbanization in developing countries: current trends, future projections, and key challenges for sustainability," Technology in Society, vol. 28, no. 1-2, pp. 63-80, 2006.

[81] S. Démurger, "Infrastructure development and economic growth: an explanation for regional disparities in China?," Journal of Comparative Economics, vol. 29, no. 1, pp. 95-117, 2001.

[82] M. F. Dulaimi, Y. F. Y. Ling, G. Ofori et al., "Enhancing integration and innovation in construction," Building Research and Information, vol. 30, no. 4, pp. 237-247, 2002.

[83] X. Xue, R. Zhang, X. Zhang, R. J. Yang, and H. Li, "Environmental and social challenges for urban subway construction: an empirical study in China," International Journal of Project Management, vol. 33, no. 3, pp. 576-588, 2015.

[84] S. L. Cutter, C. G. Burton, and C. T. Emrich, "Disaster resilience indicators for benchmarking baseline conditions," Journal of Homeland Security and Emergency Management, vol. 7, no. 1, p. 51, 2010.

[85] H. Chen, B. Jia, and S. S. Y. Lau, "Sustainable urban form for Chinese compact cities: challenges of a rapid urbanized economy," Habitat International, vol. 32, no. 1, pp. 28-40, 2008.

[86] L. Y. Shen, J. J. Ochoa, M. N. Shah, and X. Zhang, "The application of urban sustainability indicators-A comparison between various practices," Habitat International, vol. 35, no. 1, pp. 17-29, 2011.

[87] R. T. Warne, C. Nagaishi, M. K. Slade, P. Hermesmeyer, and E. K. Peck, "Comparing weighted and unweighted grade point averages in predicting college success of diverse and lowincome college students," NASSP Bulletin, vol. 98, no. 4, pp. 261-279, 2014. 


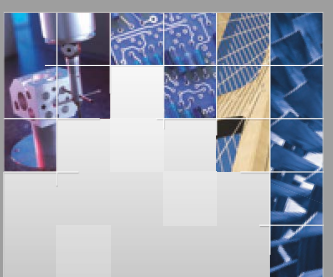

\section{Enfincering}
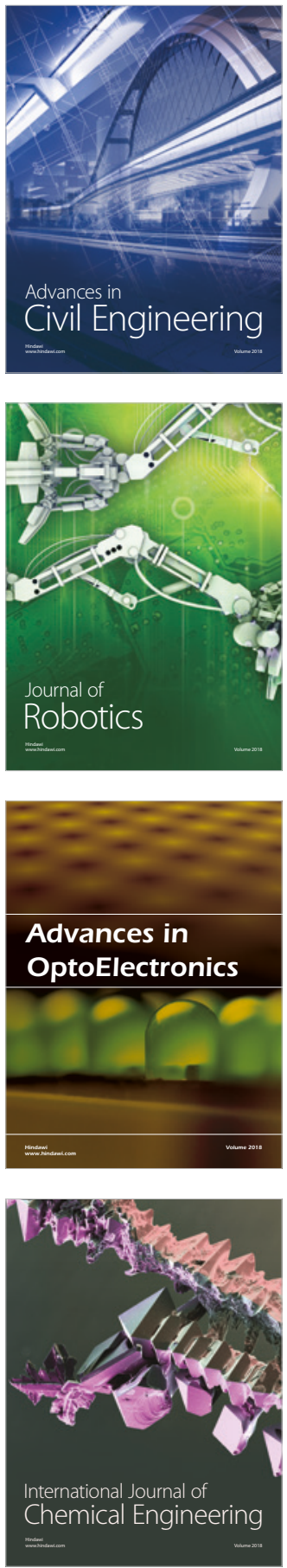

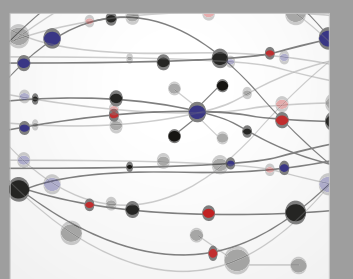

\section{Rotating \\ Machinery}

The Scientific World Journal

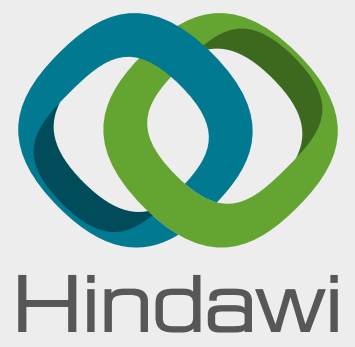

Submit your manuscripts at

www.hindawi.com
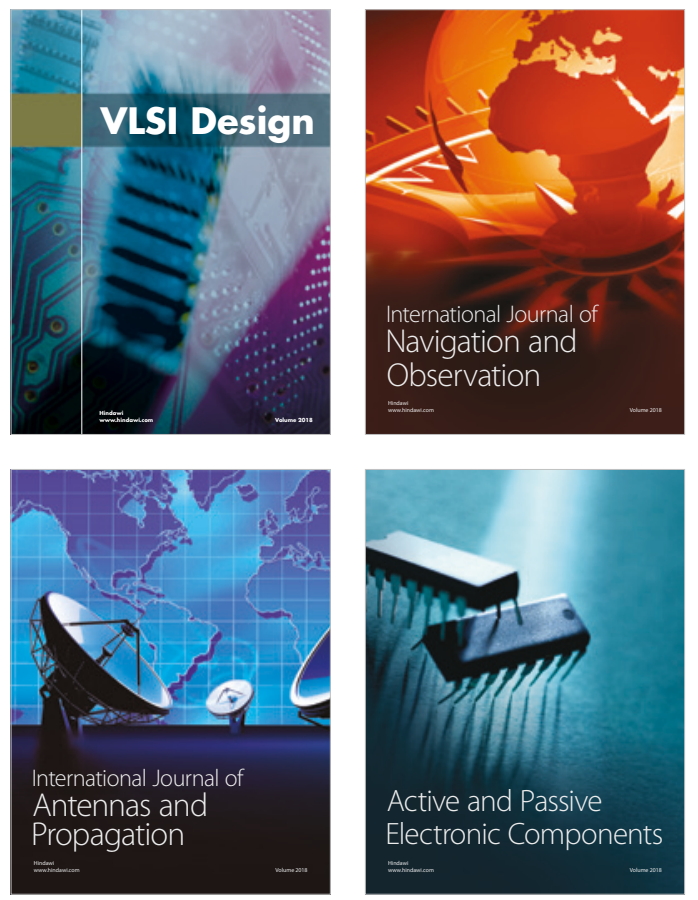
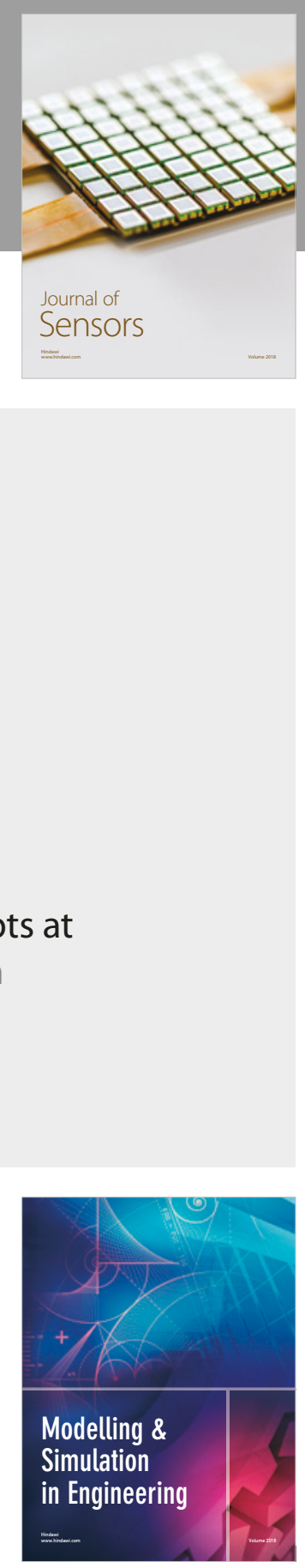

\section{Advances \\ Multimedia}
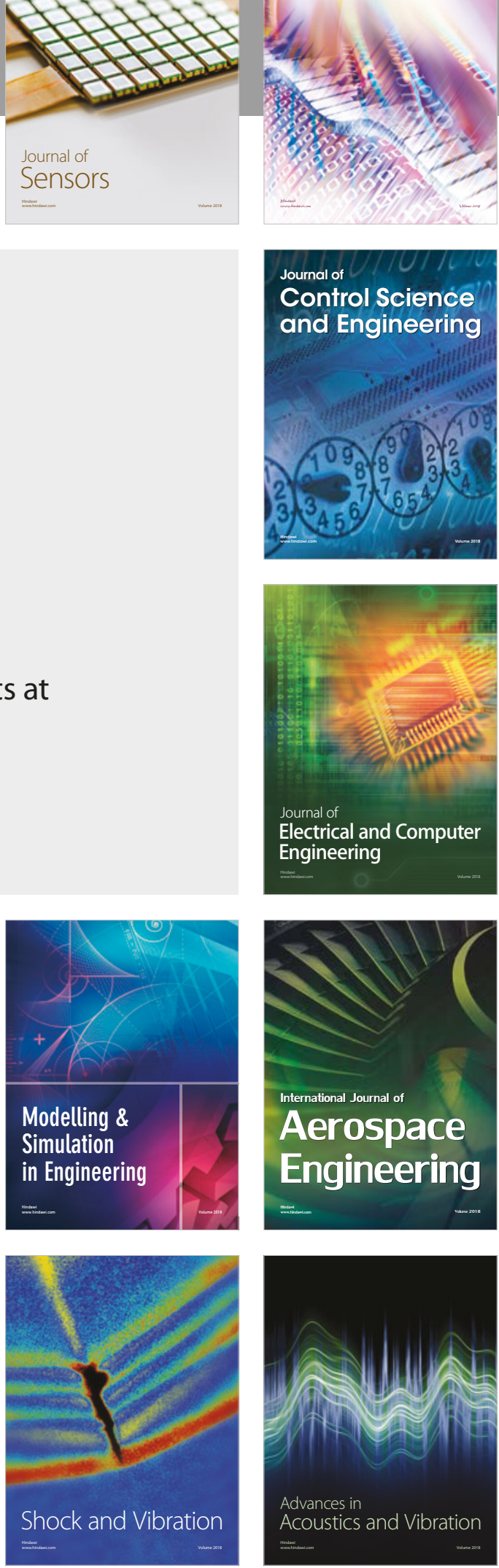